INSTITUT NATIONAL DE LA STATISTIQUE ET DES ETUDES ECONOMIQUES

Série des Documents de Travail du CREST

(Centre de Recherche en Economie et Statistique)

\author{
$n^{\circ}$ 2002-37 \\ Trade Liberalization and the \\ Internal Geography of Countries
}

\author{
M. CROZET \\ P. KOENIG-SOUBEYRAN 2
}

Les documents de travail ne reflètent pas la position de l'INSEE et n'engagent que leurs auteurs.

Working papers do not reflect the position of INSEE but only the views of the authors.

1 TEAM, University of Paris 1. Email : crozet@univ-paris 1.fr

${ }^{2}$ CREST and TEAM, University of Paris 1. Email : psk@ensae.fr 


\title{
Trade Liberalization and the Internal Geography of Countries
}

\author{
Matthieu Crozet* Pamina Koenig-Soubeyran ${ }^{\dagger}$
}

30th October 2002

\begin{abstract}
This paper focuses on the relation between trade openness and the location of economic activity in a country. We extend a new economic geography model in which trade liberalization affects both the agglomeration and dispersion forces that shape the spatial equilibrium. In the case where the two domestic regions are equidistant from foreign markets, trade openness fosters spatial concentration. When one of the regions has a pronounced advantage in terms of its access to international markets, we show that trade openness generally favors the border region, unless competition pressure from foreign firms is too high.
\end{abstract}

\section{Résumé}

Cet article se propose d'étudier la relation théorique entre ouverture au commerce et localisation des activités à l'intérieur d'un pays. Nous développons une extension d'un modèle d'économie géographique dans lequel l'ouverture au commerce affecte à la fois les forces d'agglomération et de dispersion qui sous-tendent l'équilibre spatial. Lorsque les deux régions du pays domestique sont situées à égale distance des marchés étrangers, la libéralisation du commerce provoque la concentration de l'activité industrielle dans une des deux régions du pays domestique. Dans le cas où une des deux régions possède un avantage en termes d'accès aux marchés internationaux, l'ouverture encourage l'agglomération des activités dans la région frontalière, sauf si la pression concurrentielle en provenance de l'étranger est trop soutenue.

Keywords: economic integration, internal geography, agglomeration J.E.L. Classification: F12, F15, R12

${ }^{*}$ TEAM, University of Paris I, 106-112 bd de l'hôpital 75647 Paris Cedex 13, France. Email: crozet@univparis1.fr

${ }^{\dagger}$ CREST and TEAM, University of Paris I, timbre J360, 15 bd Gabriel Péri, 92245 Malakoff Cedex, France. Email: pks@ensae.fr 


\section{Introduction}

The need to restructure a large number of European policies before launching the final part of the enlargement of the European union (EU) gathers consensus among European policy makers. One of the area of European action on which particular attention will be driven are the European regional policies, and two new sources of European funding have already been created specifically for these countries in order to finance regional development.

In this context, it appears relevant to go one step further and to analyze the link between the economic integration of the Central and Eastern European countries (CEECs) with the EU and the economic geography of these countries: How does trade liberalization impact on regional development patterns within countries?

The relation between trade and the location of production inside countries has been explicitly studied by recent models of the new economic geography literature, based on the original model of Krugman (1991). Indeed, Krugman and Livas (1996), in a two countries three-region framework, suggest that a decrease in international transaction costs between two countries may foster the dispersion of economic activity inside the home country. Conversely, Alonso-Villar (2001), Monfort and Nicolini (2000), and Paluzie (2001), respectively in a three-country, twocountry four-region, and in a two-country three-region framework, show that trade liberalization is more likely to enhance agglomeration of economic activity inside the country opening to trade.

Some empirical work on the topic validate Krugman and Livas's result: Ades and Glaeser (1995) study a 85 countries sample and find a negative relationship between trade and urban concentration. Hanson (2001) analyzes the consequences of the north-american integration process on the location of activity inside Mexico. He finds a decreasing urban concentration: industries leave Mexico-city to locate closer to the American border.

However, Henderson (1996), in commenting Krugman and Livas's model, suggests to bring one more element to the framework. He underlines that the impact of an increase in trade depends on the internal geography of the country: "The impact of trade on national space is situation-specific, depending on the precise geography of the country. (...) In thinking about urban concentration, we may want a more generic or general framework". Our focus in this paper is twofold: first, using the original new economic geography framework (Krugman, 1991), we develop a theoretical model containing two countries and three regions (domestic regions 1 and 2 and foreign region 0 ). We analyze the impact of trade liberalization on the internal geography of the domestic country, using a domestic country in which both regions are equidistant from the 
border. We observe that, in a model in which both the dispersion and agglomeration of economic activity are driven by endogenous elements, trade liberalization leads to the concentration of activity inside the domestic country. Note that Paluzie (2001) already went through these steps. In her model, the predicted outcome is agglomeration, but she does not study thoroughly the reasons for which her result differs from Krugman and Livas's. In contrast, in our paper section 4 is devoted to put side by side our model and Krugman and Livas's, in order to evaluate the origins of the difference in outcomes.

Our second focus in this paper concerns the configuration in which both domestic regions do not have the same access to the foreign market. Coming up to Henderson's expectations, we generalize the model exposed in sections (2) and (3) to look at how the result is altered by having a heterogeneous domestic country opening to trade: in this case, we show that trade liberalization is likely to favor the development of border regions.

\section{The model}

This section exposes a model previewed by Paluzie (2001), which is a simple extension of Krugman's (1991) model to a two-country framework; a domestic country, containing two regions, opens to trade with an exogenous foreign country. We want to focus on the evolution of the economic geography inside the domestic country during the process of trade liberalization.

Consider two countries: a domestic country, containing two regions, labeled 1 and 2, and a foreign country, labeled 0 . There are two sectors: one is a monopolistically competitive manufacturing sector, which produces a differentiated good and stands for all increasing to scale production activities in the economy. The other is the constant return to scale, perfectly competitive sector, which produces a homogeneous good. We will assimilate it to the agricultural sector. Factors are specific to each sector. The agricultural and the manufacturing goods are traded both interregionally and internationally.

The foreign country is totally exogenous: it contains $L_{A 0}$ agricultural workers and $L_{0}$ manufacturing workers, which are all immobile. In the domestic country, regional supply of A labor is fixed: the two domestic regions contain respectively $L_{A 1}$ and $L_{A 2}$ workers, which are immobile. In the domestic manufacturing sector, only the total amount of manufacturing labor is fixed: the country has $L$ manufacturing workers, distributed among regions: $L=L_{1}+L_{2}$. The interregional distribution of industrial workers is endogenous: workers are mobile and migrate between the regions 1 and 2 according to the interregional real wage difference. For the rest of 
the paper, we normalize the total number of industrial workers in the domestic country: $L=1$. We set the share of industrial workers in region 1 equal to $\lambda: L_{1}=\lambda, L_{2}=1-\lambda$.

The spatial framework of the model is introduced through the use of a transaction cost variable, representing distance between cities and barriers to trade. As in similar models, a variety produced in region $r$ is sold by the firm at mill-price and the entire transaction cost is borne by the consumer. We use an "iceberg"-type transaction cost variable, which means that a fraction of the shipped good melts away during the journey. When 1 unit is shipped, priced $p$, only $1 / T$ actually arrives at destination. Therefore, in order for 1 unit to arrive, $T$ units have to be shipped, increasing the price of the unit received to $p T$. Trade in the industrial good bears transaction costs, which differ across regions: $T_{12}$ is the internal transaction cost, which applies to interregional domestic trade (with $T_{12}=T_{21}$ ). $T_{01}$ and $T_{02}$ are respectively the external transaction costs applying to each domestic region's trade with the foreign country. We assume the agricultural good's trade is costless, both interregionally and internationally. Therefore, its price equalizes everywhere: $p_{A 1}=p_{A 2}=p_{A 0}$. The agricultural good is produced under perfect competition, and we choose technical coefficients equal to 1 . As a result in each region $p_{A}=w_{A}$. Finally, we use the agricultural good as a numéraire, therefore $w_{A}=1$ in each region.

\subsection{Consumers and Price Indices}

Every consumer has the same Cobb-Douglas utility function:

$$
U=M^{\mu} A^{1-\mu}, \text { with } 0<\mu<1
$$

$\mathrm{M}$ is a composite index of the consumption of the manufactured good, $\mathrm{A}$ is the consumption of the agricultural good. A share $\mu$ of expenditures goes to manufactured goods, and $1-\mu$ to the agricultural good. The composite index $\mathrm{M}$ is the following CES function:

$$
M=\left[\sum_{i=1}^{n} c_{i}^{\frac{\sigma-1}{\sigma}}\right]^{\frac{\sigma}{\sigma-1}}
$$

where $c_{i}$ represents the consumption of a variety $i$ of the manufactured good, and $\sigma$ is the elasticity of substitution between two varieties $(\sigma>1)$. Given income $Y$, each consumer maximizes his utility under the budget constraint $Y=p_{A} A+\sum_{i=1}^{n} c_{i} p_{i}$. We get the following demand function, representing demand emanating from consumers of region $s$, addressed to a producer 
$i$ located in region $r$ :

$$
c_{i, r s}=\frac{p_{i r s}^{-\sigma}}{\sum_{r=0}^{R} \sum_{i=1}^{n_{r}}\left(p_{i r s}\right)^{1-\sigma}} \mu Y_{s}, \quad r, s=0,1,2 .
$$

Equation (3) contains the spatial framework: there are $R$ regions, each of them producing $n_{r}$ varieties of the manufacturing good. The iceberg transport technology implies that the price of each variety $i$ produced in $r$ and sold in $s$ contains the mill price and the transaction cost: $p_{i r s}=p_{r} T_{r s}$ (because of the symmetry of all varieties produced in the same region, from now on we omit the variety index). We use $T_{r s}$ as a general expression which represents either $T_{12}$, $T_{01}$ or $T_{02}$, assuming that $T_{r r}=1$ and (until section 5) that $T_{01}=T_{02}>T_{12}$. Using (2) and (3), we are thus able to derive the following industrial price index for each region $s$ :

$$
G_{s}=\left[\sum_{r=0}^{R} n_{r}\left(p_{r} T_{r s}\right)^{1-\sigma}\right]^{\frac{1}{1-\sigma}}
$$

Individual demand (3) can now be written

$$
c_{r s}=\frac{\left(p_{r} T_{r s}\right)^{-\sigma}}{G_{s}^{1-\sigma}} \mu Y_{s} \quad r, s=0,1,2
$$

\subsection{Producers}

Manufactured goods are produced in a monopolistically competitive industry, following the Dixit and Stiglitz (1977) framework. Each producer has the same production function, expressed in terms of manufacturing labor : $l=\alpha+\beta q$, where $l$ is the total cost, in terms of labor, of producing $q$ varieties. It contains a fixed $\operatorname{cost} \alpha$ and a marginal cost $\beta$ per additional unit produced. Each producer maximizes his profits. As usual in the Dixit and Stiglitz (1977) model, we obtain constant mark-up equations:

$$
p_{r}=\left(\frac{\sigma}{\sigma-1}\right) w_{r} \beta
$$

where $p_{r}$ is the price of a variety produced in $r$ and $w_{r}$ is the manufacturing wage in region $r$. The equilibrium output of a firm producing in region $r$ is derived from the free entry condition:

$$
q_{r}^{*}=\frac{\alpha(\sigma-1)}{\beta}
$$


and the equilibrium on each region's labor market allows us to obtain the equilibrium number of firms in each region:

$$
n_{r}=\frac{L_{r}}{\alpha \sigma}
$$

where $L_{r}$ is the total number of manufacturing workers in region $r$.

\subsection{Short-Term Equilibrium}

We now want to fully determine the short-term equilibrium. We derive, for a given distribution of labor between regions 1 and 2, the value of $w_{r}$ that verifies equations (5), (6), (7), (8) and the equilibrium condition on the goods' market. The manufacturing wage equation for each region $r$ is thus:

$$
w_{r}=\frac{1}{\beta}\left(\frac{\sigma-1}{\sigma}\right)\left[\frac{\mu \beta}{\alpha(\sigma-1)}\left(\sum_{j=0}^{R} Y_{j} G_{j}^{\sigma-1} T_{j r}^{1-\sigma}\right)\right]^{1 / \sigma}
$$

with $Y_{r}=w_{r} L_{r}+w_{A r} L_{A r}$, and $w_{A r}$ equal to 1 because we chose it as a numéraire. Equation (9) is a typical wage equation in new economic geography models (see Fujita, Krugman and Venables, 1999). It explains that the largest the number of consumers and the lowest the number of competitors in regions with low transaction costs to $r$, the highest the nominal wage that a firm producing in $r$ can pay will be: indeed, the nominal wage in region $r$ tends to be higher if incomes in other regions with low transaction costs to $r$ are high. On the other side, it tends to be lower if other regions with low transaction costs to $r$ contain a large number of firms (the region's industrial price index $G_{j}^{\sigma-1}$ may be regarded as an index of concentration).

We are now able to characterize entirely the equilibrium variables in our two country-three region setting, for a given spatial distribution of workers. Regional incomes are:

$$
\begin{aligned}
Y_{1} & =w_{1} \lambda+L_{A 1} \\
Y_{2} & =w_{2}(1-\lambda)+L_{A 2} \\
Y_{0} & =w_{0} L_{0}+L_{A 0}
\end{aligned}
$$

Nominal wages are the solution of the following system, where $G$ and $Y$ have to be substituted 
for as functions of wages using (4), (6), (8) and $Y_{r}=w_{r} L_{r}+L_{A r} w_{A r}$ (see appendix) ${ }^{1}$ :

$$
\begin{aligned}
& w_{1}=\frac{1}{\beta}\left(\frac{\sigma-1}{\sigma}\right)\left[\frac{\mu \beta}{\alpha(\sigma-1)}\left(Y_{0} G_{0}^{\sigma-1} T_{0}^{1-\sigma}+Y_{1} G_{1}^{\sigma-1}+Y_{2} G_{2}^{\sigma-1} T_{12}^{1-\sigma}\right)\right]^{1 / \sigma} \\
& w_{2}=\frac{1}{\beta}\left(\frac{\sigma-1}{\sigma}\right)\left[\frac{\mu \beta}{\alpha(\sigma-1)}\left(Y_{0} G_{0}^{\sigma-1} T_{0}^{1-\sigma}+Y_{1} G_{1}^{\sigma-1} T_{12}^{1-\sigma}+Y_{2} G_{2}^{\sigma-1}\right)\right]^{1 / \sigma} \\
& w_{0}=\frac{1}{\beta}\left(\frac{\sigma-1}{\sigma}\right)\left[\frac{\mu \beta}{\alpha(\sigma-1)}\left(Y_{0} G_{0}^{\sigma-1}+Y_{1} G_{1}^{\sigma-1} T_{0}^{1-\sigma}+Y_{2} G_{2}^{\sigma-1} T_{0}^{1-\sigma}\right)\right]^{1 / \sigma}
\end{aligned}
$$

The industrial price indices are then given by:

$$
\begin{aligned}
& G_{1}=\left(\frac{\sigma \beta}{\sigma-1}\right)\left(\frac{1}{\alpha \sigma}\right)^{1 / 1-\sigma}\left[L_{0}\left(w_{0} T_{0}\right)^{1-\sigma}+\lambda w_{1}^{1-\sigma}+(1-\lambda)\left(w_{2} T_{12}\right)^{1-\sigma}\right]^{1 / 1-\sigma} \\
& G_{2}=\left(\frac{\sigma \beta}{\sigma-1}\right)\left(\frac{1}{\alpha \sigma}\right)^{1 / 1-\sigma}\left[L_{0}\left(w_{0} T_{0}\right)^{1-\sigma}+\lambda\left(w_{1} T_{12}\right)^{1-\sigma}+(1-\lambda) w_{2}^{1-\sigma}\right]^{1 / 1-\sigma} \\
& G_{0}=\left(\frac{\sigma \beta}{\sigma-1}\right)\left(\frac{1}{\alpha \sigma}\right)^{1 / 1-\sigma}\left[L_{0} w_{0}^{1-\sigma}+\lambda\left(w_{1} T_{0}\right)^{1-\sigma}+(1-\lambda)\left(w_{2} T_{0}\right)^{1-\sigma}\right]^{1 / 1-\sigma}
\end{aligned}
$$

We finally derive the real wage of each domestic region, which is made of the nominal wage deflated by the price index:

$$
\begin{aligned}
& \omega_{1}=\frac{w_{1}}{G_{1}^{\mu}} \\
& \omega_{2}=\frac{w_{2}}{G_{2}^{\mu}}
\end{aligned}
$$

\subsection{Long-Term Equilibrium}

One can see that if $\lambda=1 / 2$ (and if $L_{A 1}=L_{A 2}$ ), $\omega_{1}=\omega_{2}$ : when the industrial workforce is equally distributed between domestic regions, the real wages are equalized and there is no incentive for workers to move. But what happens if we move one worker from region 2 to region 1? This move will create a real wage differential that may either incite more people to move, or on the contrary it may lower the real wage in the destination region, in which case the equally distributed configuration would be a stable equilibrium. We assume that industrial workers move between the two regions according to the following migration dynamics:

$$
\frac{d \lambda}{d t}=\omega_{1}-\omega_{2}
$$

\footnotetext{
${ }^{1}$ The question of the unicity of the solution is difficult to solve when there is more than one equation involved, and we leave it aside for the moment. We explain the procedure for solving numerically for $w_{1}$ and $w_{2}$ in the appendix.
} 
We want to study the relationship between the real wage differential and the fraction of industrial workers living in region 1. We want to identify the spatial equilibria of the model, thus the distributions of workers for which no worker may get a higher real wage by changing location. The equilibrium distributions of the workforce thus consist of the values of $(\lambda, 1-\lambda)$ for which either $\omega_{1}-\omega_{2}=0$ and $\lambda \in(0,1)$, or $\omega_{1}-\omega_{2} \geq 0$ and $\lambda=1$, or $\omega_{1}-\omega_{2} \leq 0$ and $\lambda=0$.

Unfortunately, as typically in new economic geography models based on the original Krugman (1991) framework, $\omega_{1}-\omega_{2}$ is not a simple function of $\lambda$ : we are unable to tell precisely for what values of the parameters of the model the spatial equilibria are reached. In the next section we will thus use numerical simulations in order to look at the shape of the real wage differential function.

The evolution of the real wage differential $\omega_{1}-\omega_{2}$ and the equilibrium spatial distribution inside the domestic country depend on the interaction of agglomeration and dispersion forces appearing in the equations we derived above. On the one side, agglomeration forces express the fact that firms and consumers are interested in locating in the same region, because of cost and demand externalities: in equations (13) and (14), the demand externality emphasizes that a large number of consumers in a region $r$ represents high local expenditure, allowing firms to pay higher wages and thus attracting more firms. The cost externality appears in equations (16), (17) and (18): a high number of firms implies a lot of locally produced varieties, thus a lower price index and more consumers.

On the other side, the dispersion force emanates from the high competition on the good and the factor markets when industrial activity is concentrated in one location: equations (13) and (14) point that the nominal wage of a region diminishes with the increase in competition, and this leads firms to delocate towards the remote market in order to benefit from lower competition on that market.

Which equilibrium configuration is finally reached depends on the parameters of the models, and specifically on the level of interregional and international transaction costs. In the next section we will consider an economic integration between the domestic and the foreign country, illustrated through a decrease of $T_{01}$ and $T_{02}$. We will focus on determining how the presence of a foreign country impacts the internal geography of the domestic country. 
Figure 1: Real wage difference for three different external transaction costs

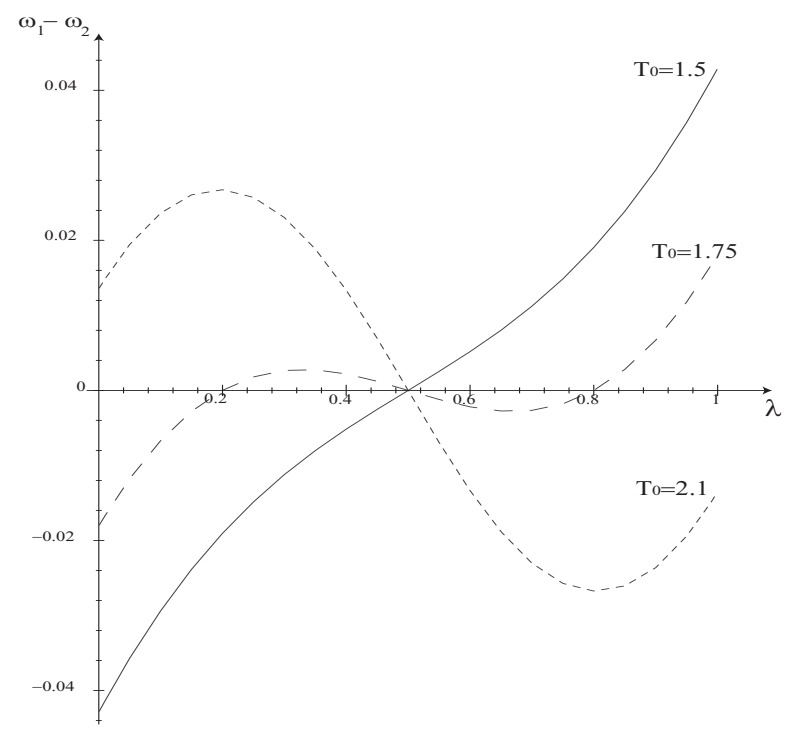

\section{Trade Liberalization}

This section considers the effect of lowering the international transaction cost on the spatial distribution of activity, in the case of a homogeneous country: the two domestic regions have the same access to foreign markets $\left(T_{01}\right.$ and $T_{02}$ are set equal to $\left.T_{0}\right)$. We explain how we draw the real wage differential curves. For a given value ${ }^{2}$ of $T_{0}$, we numerically solve $w_{1}$ and $w_{2}$ for a range of values of $\lambda \in(0,1)$. We then substitute the obtained $w_{1}$ and $w_{2}$ into $\omega_{1}-\omega_{2}$ in order to plot one of the above curves. As shown in figure (1), this is done for three different values of $T_{0}$.

Let us analyze figure (1) by starting where workers are symmetrically distributed among regions: $\lambda=0.5$. This configuration is an equilibrium, but it will only be stable if, for a marginal increase in $\lambda$, the real wage difference becomes negative. The migration of workers will then bring the distribution of workers back to the symmetrical configuration.

The situation in which the domestic country is closest to autarky is illustrated by the dotted curve, drawn for $T_{0}=2.1$ (which means that only $1 / 2.1=0.47$ of the shipped quantity arrives at the final destination, corresponding to a transaction cost of $53 \%$ ). For this level of transaction costs, the dispersed configuration is the only stable equilibrium ${ }^{3}$. The dashed curve illustrates

\footnotetext{
${ }^{2}$ The values of the other parameters are: $\sigma=6, \beta=4 / 5, \mu=0.4, \alpha=0.4 / 5, T_{12}=1.75, L_{0} / L=10$.

${ }^{3}$ Figure (1) is drawn for a value of $T_{12}$ for which industry is dispersed in autarky $\left(T_{0}=\infty\right)$. Similar results are obtained for lower values of $T_{12}$, but they are not showed here. The results are not as visible because the
} 
the situation when the economy opens slightly. There are now five equilibria, of which three are stable, and two unstable. While the symmetric equilibrium is still stable, the agglomerated configuration (in either region) has become stable as well. Finally, the more trade barriers are decreased, the more the curve turns upwards; when it comes to cross the $x$ axis with a positive slope (the level $T_{0}=1.5$ corresponds to a transaction cost of $40 \%$ ), the only stable outcome are the two agglomerated configurations. We thus highlight this interesting result: according to our simulations, an economic integration is most likely to lead the domestic industrial sector to be spatially concentrated.

Figure 2: Bifurcation diagram

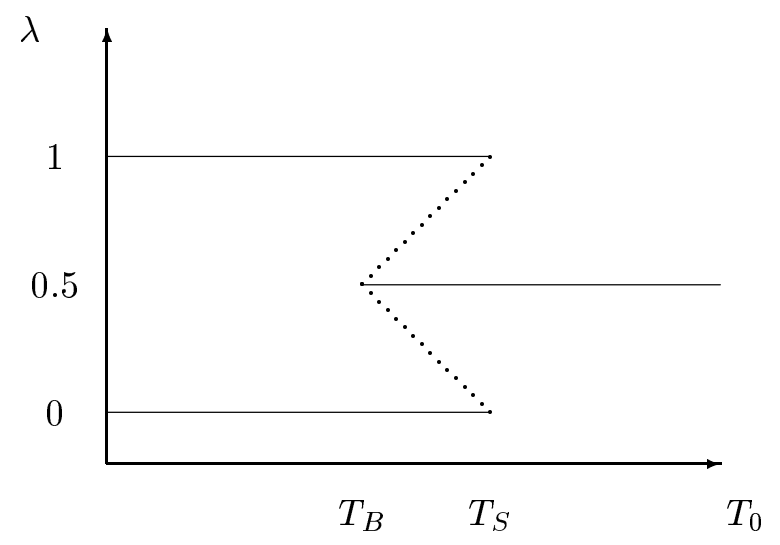

Figure (2) summarizes how the types of equilibria vary with external transaction costs (solid lines indicate stable equilibria, broken lines unstable): for sufficiently high $T_{0}$, there is a unique stable equilibrium in which the economy is evenly divided between the regions. When $T_{0}$ decreases below some threshold value ( $T_{S}$, the sustain point), new stable equilibria appear in which all manufacturing is concentrated in one of the regions. When a second threshold value ( $T_{B}$, the break point) is attained by lowering $T_{0}$, the symmetric equilibrium becomes unstable, leaving the agglomerated configurations as the only stable outcomes.

Note that simulations' results show that the values of the sustain and break point are influenced by the parameters of the model. First, the lower is $\sigma$, the higher is the value of the sustain and break points. Indeed, a low value of $\sigma$ indicates a high degree of product differentiation: in other words, the more products are differentiated, the more firms are incited to concentrate production, even if transaction costs are high. Second, the values of the sustain and break points

economy is already agglomerated. 
increase with the value of $\mu$, the share of expenditure going to manufactured goods. The larger the share of manufacturing goods, the stronger are cost and demand externalities which lead firms to concentrate production.

\section{The forces at stake}

What mechanisms explain this outcome? The decrease of the external transaction cost allows two additional elements to impact on the domestic economy: foreign demand and foreign supply. On the one side, having an access to a large exterior market lowers the incentive for domestic firms to locate near domestic consumers, which represent a smaller share of their sales. Thus the domestic demand externality is weakened by the presence of the foreign demand (in equations (13) and (14), income from the foreign country becomes a more important part of total demand). For similar reasons, the domestic cost externality is weakened by the presence of the foreign supply: the foreign firms now represent a much more important share of the total supply available to domestic consumers (in equations (16), (17) and (18), the presence of the foreign firms now constitutes the main elements that drives the price indices down).

On the other side, trade liberalization also affects the competition effects within the domestic country. The competition exerted by foreign firms on the domestic market is large compared to the competition of other domestic firms. Therefore, the presence of the foreign supply lowers the need for domestic firms to locate far from domestic competitors, and thus lowers the need to disperse economic activity (in equations (16), (17) and (18), as stated before, the presence of foreign firms lowers both price indices, which then diminish $w_{1}$ and $w_{2}$ ).

It finally appears that while foreign demand and foreign supply decrease both the agglomeration and the dispersion forces, the simulations show that in the end, a strong economic integration has more effect on the dispersion force: as a result the domestic economy becomes concentrated in only one location.

\section{Comparisons}

\subsection{Differences under autarky}

The purpose of this paper is to investigate the relation between trade liberalization and the reshaping of the internal geography of countries, using the original model of the new economic geography. Krugman and Livas (1996) already analyzed the same problematic in a similar 
framework. However, their result differs from ours as to the evolution of the domestic spatial equilibrium configuration. While we observe agglomeration as a final outcome, their model concludes to the dispersion of economic activity.

The reason why we obtain such differing results lies in the hypotheses driving the dispersion of the industrial sector. In Krugman and Livas's modeling (henceforth KL96), there is no local immobile market to provide an incentive for firms to delocate to the peripheral region. Instead, an exogenous congestion force leads firms to move to the remote region when the cost of being agglomerated is too high. The crucial point remains in the fact that KL96's congestion force does not depend on transaction costs. Hence, the decrease of external transaction costs may only have an impact on the incentives of firms and consumers to locate near each other, i.e. on the agglomeration force. The impact of trade liberalization is thus very different in both models. Economic integration, through the increase of exports (foreign demand) and imports (foreign supply), lowers agglomeration forces inside the country. While it also lowers dispersion forces in our model, in KL96's model the dispersion force is not impacted at all.

As a result, in KL96 the only stable equilibrium after trade liberalization is a dispersed distribution of the industrial sector. In contrast, the framework we propose in this paper is based on the same forces as those of new economic geography models of the Krugman (1991) type (henceforth K91). Therefore, the final outcome bears the characteristic of being the result of the interaction of two endogenous forces, and in this sense it is a more general framework.

Note that this difference is visible when comparing both models in their autarkic two-region version (by setting the external transaction cost to $+\infty$ ). While K91 concludes that a decrease in internal transaction costs will lead to more agglomeration, in KL96 the autarkic country will see its economic activity getting more dispersed. Two features of the KL96 model explain this difference in outcomes: KL96 contains only one sector, which exhibits increasing returns-to-scale, and it comprises only mobile workers. Thus, without the presence of the urban congestion cost, the economy would be concentrated in one of the regions for all values of the internal transaction cost.

To illustrate this characteristic, let us look at the configuration of the domestic economy, in both models, according to the value of the internal transaction cost. We want to identify the threshold value of $T_{12}$ at which the agglomerated equilibrium switches from unstable to stable (the sustain point of the economy according to $T_{12}$ ). We thus set the domestic economy in an agglomerated configuration (for example in region 1), and determine the conditions under which region 1 real wage $\left(\omega_{1}\right)$ is higher than region $2\left(\omega_{2}\right)$ : for all values of $T_{12}$ for which $\omega_{1} \geq \omega_{2}$, 
Figure 3: Sustain point for K91 and KL96

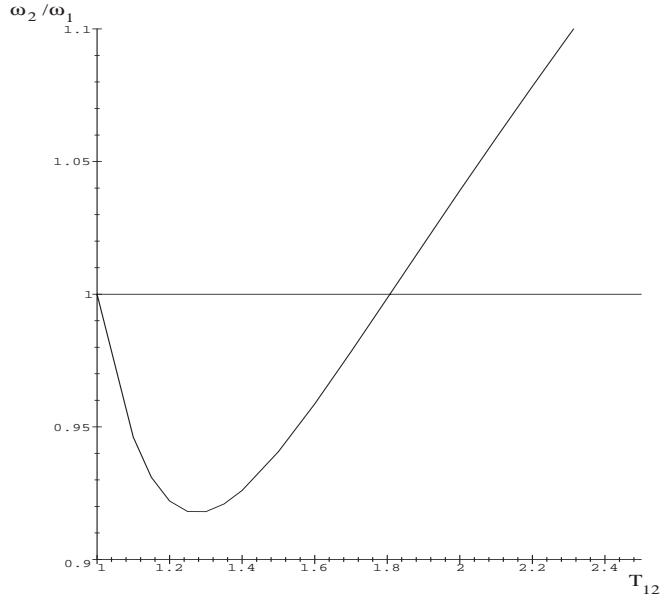

(a) K91

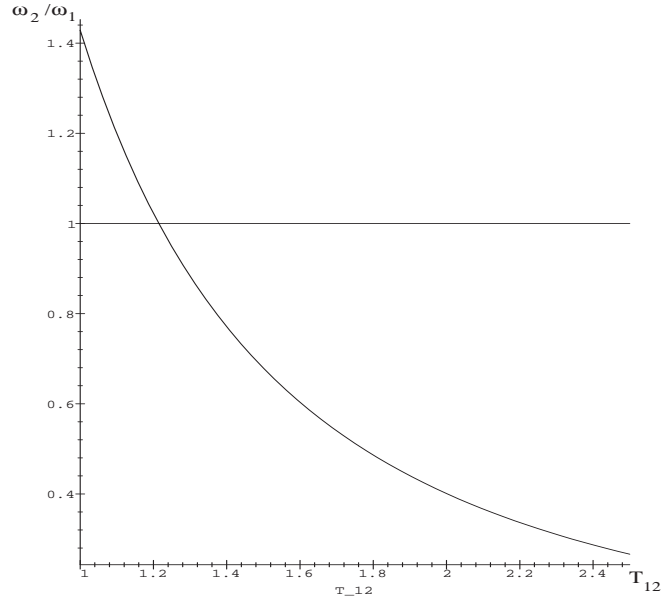

(b) KL96

the agglomerated pattern is sustainable, because industrial workers will not migrate to region 2. Figure (3) portrays the sustain point in both models according to $T_{12}$. The U-shape of the $\frac{\omega_{2}}{\omega_{1}}$ curve in K91 represents the agglomeration-dispersion pattern. When the internal transport $\operatorname{cost} T_{12}$ equals 1 , space plays no role and real wages are identical. At the right of this point, the curve is downwards-sloping: a slight increase in $T_{12}$ augments both agglomeration and dispersion forces, but not in the same measure. Demand and cost externalities have more influence on the economy and foster a strong asymmetric configuration, until the relative strength of the forces inverses. The upwards-sloping part of the curve depicts a relatively more important increase in the dispersion forces, which finally make the asymmetric pattern unstable. To the right of the sustain point, industrial activity is symmetrically distributed among regions.

The $\frac{\omega_{2}}{\omega_{1}}$ curve in KL96 has two distinct features. First, it does not bear the upward-sloping part of the K91 U-shaped curve, which means that there is no dispersion of the economy for high values of $T_{12}$. Second, at low values of $T_{12}$, concentration of industrial activity is not a stable equilibrium anymore (Numerical investigations similar to those exposed in figure (1) indicate that low values of $T_{12}$ lead to the dispersion of industrial activity). As explained above, the presence of the urban congestion cost discourages firms and consumers to support the cost of agglomeration when the internal transaction costs are very low. Hence, the reasons why we obtain, using a K91 setting, opposite results to those obtained by KL96 are already present in the basic hypotheses of the models and in the autarkic two-region settings. 


\subsection{Robustness to internal spatial configurations}

An important question arising after comparing the two models concerns the validity of our results for other values of parameters, and specifically for other values of the internal transaction cost. To answer this question, let us look again at the configuration of the domestic economy according to the value of the internal transaction cost. We want to analyze how the threshold value of $T_{12}$ at the sustain point of the economy varies with $T_{0}$.

Figure 4: Sustain point for three different external transaction costs

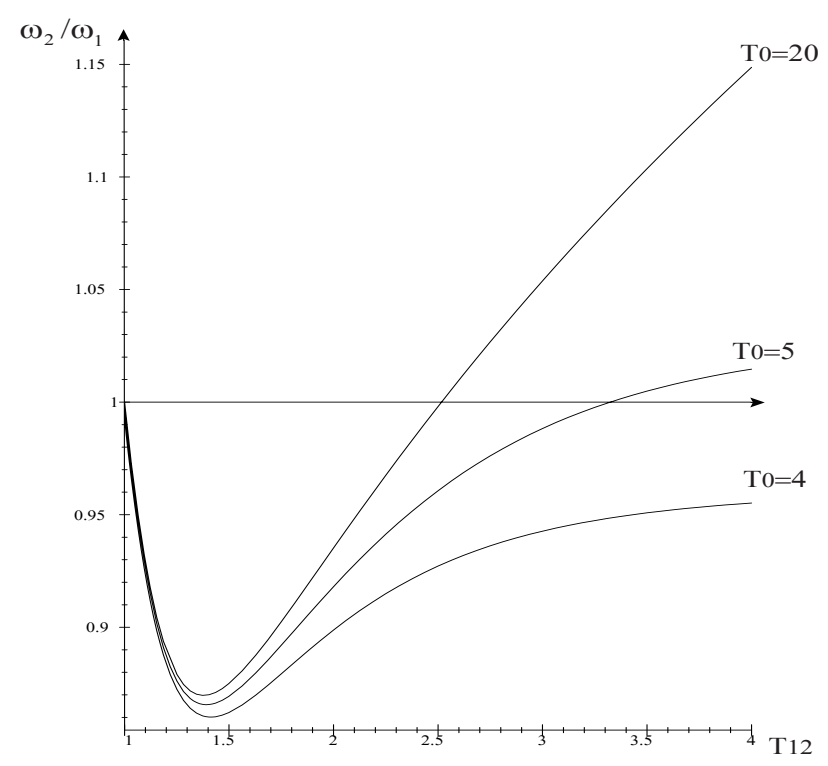

Unfortunately, the three-region framework introduces analytical difficulties that are not present in the two-region or in the four-region case. Therefore we are not able to present an analytical proof. We will instead use numerical simulations to investigate how the sustain point of the economy varies with the evolution of the external transaction cost. Figure (4) illustrates $\frac{\omega_{2}}{\omega_{1}}$ as a function of the internal transport cost $T_{12}$, and this for three different values of $T_{0}$. The first curve is drawn for a very high value of $T_{0}$, assimilated to very important barriers to trade. As explained above, $\frac{\omega_{2}}{\omega_{1}}$ is U-shaped. The second curve illustrates the same phenomenon for a lower value of $T_{0}$. The visible impact of the economic integration is to lower the right part of the precedent U-shaped curve. According to the description of the curve in the preceding sub-section, the decrease in $T_{0}$ specifically impacts the dispersion forces, because the sustain point shifts to the right of the figure. Trade openness augments the range of values of $T_{12}$ for which the economy is agglomerated, i.e. the effect of the domestic competition (lower price index) is weakened. This is even more apparent when trade openness accentuates, to the point 
that the curve doesn't display a sustain point any more: on the last curve, $\omega_{2}$ never becomes higher than $\omega_{1}$.

According to the simulations, our theoretical result appears to be robust to the spatial configuration of the domestic economy. Whatever the value of the internal transaction cost, trade liberalization is most likely to foster an economic geography concentrated in one of the two domestic locations. Note that Paluzie (2001), who previewed the theoretical result, did not investigate how international transaction costs affect the sustain point of the economy.

Our result is strengthened by Monfort and Nicolini (2000), who come to identical conclusions in a four regions' setting. They extend a Krugman (1991) framework to a two-country fourregion model and show that international integration, thus the decrease of external transaction costs, is likely to enhance agglomeration in each of the national economies. The four region setting is useful because it allows simplifications and lead to analytical solutions. However, we prefer considering a three regions model. It seems more appropriate because our main focus is centered on the economic geography of the domestic country and it allows to make direct comparisons between our result and Krugman and Livas's. Moreover, expanding the original Krugman (1991) two-region framework to a three-region framework allows us to get closer to the modeling of different and richer configurations such as the hub-city case (see Krugman, 1993). This will be particularly apparent in the next section when analyzing the case of a country containing a border region.

\section{Border regions}

We now ask the same question, but in a slightly different framework: by letting the two external transaction costs differ, we suppose that one of the domestic cities has a better access to the foreign market (region 2 for example). We specify a functional form for $T_{r s} . T_{r s}$ represents all the transaction costs and consists of a cost related to distance and, for international trade, an ad-valorem tariff. In this section we also adopt a specific and simplified representation of space à la Hotelling in which country 0 and region 1 are located at both extremes. Region 2 is the border region. The segment thus has a length equal to $d_{01}$, and the distance between 1 and 2 is $d_{01}-d_{02}$. We assume that transaction costs are a linear function of distance: $T_{12}=1+\left(d_{01}-d_{02}\right)$ and $T_{01}=1+$ tariff $+d_{01}$.

In order to understand how the economic geography of the country evolves with trade openness, as in section (3) we use numerical simulations to display the shape of the interregional real 
Figure 5: Real wage difference when the two regions have different external transaction costs

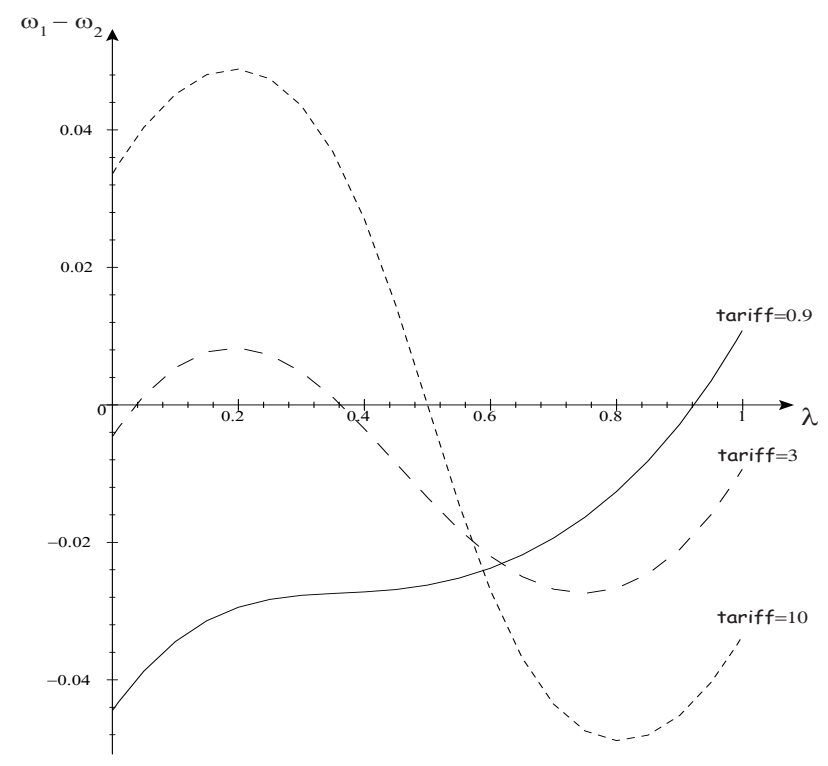

wage difference as a function of the workers distribution $\lambda$.

Theoretically, the forces impacting on the domestic economy are modified since the country now contains two heterogeneous regions. Two changes are noticeable: first, as observed in section (3), foreign demand lowers the domestic agglomeration force. However, an additional effect appears, because domestic firms may now choose to locate in the location closest to the foreign market, which is region 2 . We thus highlight one of the potential effects of trade liberalization, which is to pull domestic firms towards the border in order for them to benefit from the best access to foreign demand. Then, foreign supply lowers the domestic dispersion force. There is also an additional effect due to the heterogeneity of the regions: region 1, at the end of the segment, allows firms to locate as far as possible from the foreign competitors. Hence, trade liberalization may push domestic firms towards the remote regions, as a reaction of protection against the large foreign competition.

Figure (5), which is drawn in a similar way as figure (1), illustrates the impact of these forces according to the degree of trade liberalization. As observed in section (3), the symmetric distribution of workers is a stable equilibrium for high values of $T_{0}$. When $T_{0}$ decreases, the curve comes to cross the $x$ axis with a positive slope, meaning that only agglomerated configurations are stable equilibria. However, the curves are not symmetric anymore with respect to the value $\lambda=0.5$. The push effect of firms towards the interior region is to be seen through the shift of the dotted curve to the right: when the domestic economy is still relatively closed, the increase 
of the degree of competition driven by foreign supply dominates the pull effect. Economic activities are dispersed but there is an asymmetry leading to the location of more than $50 \%$ of the industries in region 1.

The pull effect of firms to the border region is illustrated by the shift of the dark curve to the right. When $T_{0}$ is low, the increase of demand emanating from the foreign country dominates the competition effect driven by foreign firms, and the country's economic activity is attracted to the border region. The agglomeration is the only stable equilibrium, but it has more chances to occur in the closest region to the foreign market. Figure (5) shows that the concentration of the industry will only occur in region 1 if the latter contains more than $80 \%$ of the industrial activity of the country.

The main outcome arising in this section helps to modulate our previous results. The model shows that trade liberalization may foster two effects: a pull-effect towards border regions and a push-effect inside remote regions. The strength of these phenomena will be shaped by the various elements of the model: a large foreign demand for domestic product will increase the pull of the domestic industrial sector towards low-cost access regions. Conversely, a large amount of foreign firms exporting to the domestic market may favor the development of better protected internal regions.

\section{Conclusion}

According to Henderson $(1996)^{4}$, "The impact of trade on national space is situation-specific, depending on the precise geography of the country. (...) In thinking about urban concentration, we may want a more generic or general framework". In this paper, we propose to pursue the analysis of the relation between trade liberalization and the location of production inside countries, by deepening two aspects of the issue. First, we generalize a simple extension of a Krugman (1991) model to a two countries three-region framework. In a setting in which both the agglomeration and the dispersion forces are endogenous, trade liberalization fosters spatial concentration. Second, we study the same issue in a spatially heterogeneous country. We show that when the domestic country contains a border region and a remote region, trade liberalization generally favors the development of the border region, when competition pressure from international markets is not too high.

\footnotetext{
${ }^{4}$ page 33
} 


\section{References}

Ades A. AND E. Glaeser, 1995, "Trade Circuses: Explaining Urban Giants", Quarterly Journal of Economics, 110 (1): 195-227.

Alonso Villar O., 2001, "Large Metropolises in the Third World: an Explanation", Urban Studies, 38 (8): 1359-1371.

Alonso Villar O., 1999, "Spatial Distribution of Production and International Trade: a note", Regional Science and Urban Economics, 29 (3): 371-380.

Dixit A. AND J. Stiglitz, 1977, "Monopolistic Competition and Optimum Product Diversity", American Economic Review, 67 (3): 297-308.

Fujita M., P. Krugman and A. Venables, 1999, The Spatial Economy, Cambridge, Mit Press.

Hanson G., 2001, "US-Mexico Integration and Regional Economies: Evidence from BorderCity Pairs", Journal of Urban Economics, 50 (2): 259-287.

HARRIS C., 1954, "The Market as a Factor in the Localization of Industry in the United States", Annals of the Association of American Geographers, 64: 315-348.

Helpman E., 1998, "The Size of Regions", in D. Pines, E. Sadka and I. Zilcha, eds, Topics in Public Economics, Theoretical and Applied Analysis, Cambridge, Cambridge University Press, 33-54.

Henderson V., 2002, "The Urbanization Process and Economic Growth: The So-What Question", mimeo, Brown University.

Henderson V., 1996, "Ways to Think about Urban Concentration: Neoclassical Urban Systems versus the New Economic Geography", International regional Science Review, 19 (1\&2): $31-36$.

Henderson V., T. LeE AND Y.J. LeE, 2001, "Scale Economies in Korea", Journal of Urban Economics, 49 (3): 479-504.

Krugman P., 1996, "Urban Concentration: The Role of Increasing Returns and Transport Costs", International regional Science Review, 19(1\&2): 5-30.

Krugman P., 1991, "Increasing Returns and Economic Geography", Journal of Political Economy, 99(3): 483-499.

Krugman P. and R. Livas Elizondo, 1996, "Trade Policy and Third World Metropolis", Journal of Development Economics, 49 (1): 137-150.

Krugman P. AND A. J. Venables, 1995, "Globalization and the Inequality of Nations", Quarterly Journal of Economics, 110(4): 857-880.

Monfort P. AND R. Nicolini, 2000, "Regional Convergence and International Integration", Journal of Urban Economics, 48(2): 286-306.

Nitsch V., 2001, "Openness and Urban Concentration in Europe, 1870-1990", HWWA Discussion Paper n121.

PaluzIe E., 2001, "Trade Policies and Regional Inequalities", Papers in Regional Science, 80: $67-85$.

PugA D., 1998, "Urbanization patterns: European vs less developed countries", Journal of Regional Science, 38 (2): 231-252.

Venables A., 2000, "Cities and Trade: external trade and internal geography in developing countries", in S. Yusuf, S. Evenett and W. Wu (eds.), Local Dynamics in an Era of Globalisation: 21st Century Catalysts for Developments, OUP and World Bank, Washington DC. 


\section{A Short-term equilibrium: solving numerically for $w_{1}$ and $w_{2}$}

The appendix intends to provide more details about the numerical solving procedure of the short-term equilibrium mentioned in section 2 .

We incorporate (6) and (8) into (4) and then substitute (4), (10), (11) and (12) into (13) and (14). We obtain the following two equations. In spite of their complicated aspect, equations (20) and (21) allow to derive, for a given a distribution of the industrial workforce $(\lambda, 1-\lambda)$, the nominal wages $w_{1}$ and $w_{2}$. Indeed, with numerical values for the parameters $\sigma, \mu$, for the exogenous foreign variables $\left(w_{0}, L_{0}, L_{A 0}\right)$ and for the domestic agricultural workers $\left(L_{A 1}\right.$ and $L_{A 2}$ ), equations (20) and (21) contain only two unknowns:

$$
\begin{gathered}
w_{1}^{\sigma}=\mu\left[\frac{\left(w_{0} L_{0}+L_{A 0}\right) T_{0}^{1-\sigma}}{L_{0} w_{0}^{1-\sigma}+\lambda\left(w_{1} T_{0}\right)^{1-\sigma}+(1-\lambda)\left(w_{2} T_{0}\right)^{1-\sigma}}+\frac{\left(w_{1} \lambda+L_{A 1}\right)}{L_{0}\left(w_{0} T_{0}\right)^{1-\sigma}+\lambda w_{1}^{1-\sigma}+(1-\lambda)\left(w_{2} T_{12}\right)^{1-\sigma}}\right. \\
\left.+\frac{\left(w_{2}(1-\lambda)+L_{A 2}\right) T_{12}^{1-\sigma}}{L_{0}\left(w_{0} T_{0}\right)^{1-\sigma}+\lambda\left(w_{1} T_{12}\right)^{1-\sigma}+(1-\lambda) w_{2}^{1-\sigma}}\right] \\
w_{2}^{\sigma}=\mu\left[\frac{\left(w_{0} L_{0}+L_{A 0}\right) T_{0}^{1-\sigma}}{L_{0} w_{0}^{1-\sigma}+\lambda\left(w_{1} T_{0}\right)^{1-\sigma}+(1-\lambda)\left(w_{2} T_{0}\right)^{1-\sigma}}+\frac{\left(w_{1} \lambda+L_{A 1}\right) T_{12}^{1-\sigma}}{L_{0}\left(w_{0} T_{0}\right)^{1-\sigma}+\lambda w_{1}^{1-\sigma}+(1-\lambda)\left(w_{2} T_{12}\right)^{1-\sigma}}\right. \\
\left.+\frac{w_{2}(1-\lambda)+L_{A 2}}{L_{0}\left(w_{0} T_{0}\right)^{1-\sigma}+\lambda\left(w_{1} T_{12}\right)^{1-\sigma}+(1-\lambda) w_{2}^{1-\sigma}}\right]
\end{gathered}
$$

